\title{
IMPLEMENTASI PEMBELIAN MAKANAN ONLINE MELALUI LAYANAN GO-FOOD DALAM PERSPEKTIF HUKUM ISLAM
}

\section{IMPLEMENTATION OF ONLINE FOOD PURCHASES THROUGH GO-FOOD IN THE PERSPECTIVE OF ISLAMIC LAW}

\author{
Abdullah', S. Muhlisin², W. Munawar ${ }^{3}$ \\ 1aProgam Studi Ekonomi Syariah Fakultas Ekonomi Islam Universitas Djuanda Bogor, Jl. \\ Tol Ciawi No.1 Bogor, e-mail: abdullah08@unida.ac.id \\ 2Progam Studi Ekonomi Syariah Fakultas Ekonomi Islam Universitas Djuanda Bogor, Jl. \\ Tol Ciawi No. 1 Bogor, e-mail: sofian.muhlisin@unida.ac.id \\ ${ }^{3}$ Progam Studi Ekonomi Syariah Fakultas Ekonomi Islam Universitas Djuanda Bogor, Jl. \\ Tol Ciawi No. 1 Bogor, e-mail: wildan.munawar@unida.ac.id
}

\begin{abstract}
ABSTRAK
Penelitian ini bertujuan untuk mengetahui tinjauan hukum Islam dan ikhtilaf ulama terhadap transaksi pembelian makanan melalui jasa Go-Food. Jenis penelitian ini adalah kualitatif yang menggunakan metode fenomenologi topik-topik tentang tinjauan hukum Islam terhadap jual beli makanan online melalui aplikasi Go-Food yang terdapat pada dasar hukum untuk menentu dasar hukum jual beli makanan online serta melihat ikhtilaf para ulama terhadap jual beli makanan online. Hasil penelitian menunjukkan bahwa praktik pemesanan makanan melalui Go-Food terdapat perbedaan pendapat dari para ulama. Pertama, ulama yang mengharamkan karena berdasarkan dengan hadits Nabi shallallahu 'alaihi wasallam dengan menjadikan patokan utamanya yaitu transaksi yang digunakan merupakan akad pinjaman (qardh) atau akad titipan wadi'ah. Kedua, ulama yang menghalalkan karena transaksi yang digunakan merupakan akad ijarah yang termasuk kategori sewa jasa.
\end{abstract}

Kata Kunci: Hukum Islam, Transaksi Online, Layanan Go-Food

\begin{abstract}
This study aims to determine the review of Islamic law and ulama's advice on food purchase transactions through Go-Food services. This type of research is a qualitative method that uses phenomenology methods on the topic of Islamic legal review of online food buying and selling through the Go-Food application that is on the legal basis for defining the legal basis for buying and selling food online as well as looking at the ulama's understanding of online food buying and selling. The results showed that the practice of ordering food through Go-Food there were differences of opinion from the scholars. First, the scholars who forbid it because it is based on the hadith of the Prophet sallallaahu ih alayhi wasallam by making the main benchmark that is the transaction used is a loan agreement (qord) or contract wadi'ah entrusted. Second, scholars who justify it because the transaction used is an ijarah agreement which is categorized as a service lease.
\end{abstract}

Keywords: Islamic Law, Online Transactions, Go-Food Services 
Abdullah, dkk. 2020. Implementasi Pembelian Makanan Online Melalui Layanan GoFood dalam Perspektif Hukum Islam. Jurnal Syarikah 6 (2): 151-159.

\section{PENDAHULUAN}

Perkembangan dunia teknologi informasi berbasis internet selalu membawa dua dampak yaitu positif dan negatif tergantung bagaimana seseorang memilih penggunaannya. Dampak positif yang diberikan oleh perkembangan dunia teknologi diantaranya memudahkan dalam menambah teman, berinteraksi, silaturahmi, bertukar informasi dalam beraktivitas dan menambah trend pada perkembangan teknologi saat ini dengan berbagai bentuk kreativitas manusia. Seiring dengan kemajuan teknologi, maka manusia akan semakin mudah dalam memenuhi berbagai keinginan dan kebutuhan hidupnya. Kemajuan teknologi informasi dimanfaatkan pula oleh para pelaku usaha dengan menghubungkan bidang usaha yang dijalani pada jaringan internet (online) melalui aplikasi khusus atau situs web khusus yang bisa diakses oleh para pengguna smartphone di dunia dengan cara mengunduhnya pada layanan yang ada atau dengan cara browsing, salah satunya adalah Go-Jek.

Go-Jek merupakan perusahaan di bidang transportasi yang dalam melakukan pelayanannya menggunakan kendaraan roda dua (ojek) berbasis online. Perusahaan ini didirikan oleh Nadiem Makariem pada tahun 2011 dan telah meluncurkan aplikasi mobile pada awal 2015 dengan wilayah cakupan Jakarta, Bandung, Surabaya dan Bali. Fenomena kehadiran Go-Jek ditengah masyarakat cukup dirasakan pada masyarakat Jakarta. Go-Jek di tengah kesibukan serta kepadatan kendaraan pribadi yang kerap terjadi di ibu kota, menjadi pilihan menggunakan kendaraan roda dua yang lebih cepat dan mudah menghindari kemacetan serta dapat menempuh jalan-jalan kecil, Go-Jek menjadi solusi dan penolong terutama bagi para pemburu waktu (Mu'izz \& Fitria, 2016).

Salah satu layanan yang tersedia pada aplikasi Go-Jek adalah Go-Food, yaitu fitur pesan antar (delivery) yang disediakan perusahan Go-Jek untuk membelikan dan mengantarkan makanan pesanan kepada penggunanya. Layanan tersebut melibatkan 3 (tiga) pihak, yaitu pengguna, restoran, dan pihak ojek. Mekanismenya layanan ini adalah pengguna membuka fitur Go-Food pada aplikasi Go-Jek. Kemudian, akan muncul daftar restoran dan rumah makan serta harga makanan kemudian pengguna memilih menu makanan yang akan dipesan. Pihak ojek yang menerima pesanan konsumen akan membeli makanan dan membayar dulu harganya (dibayar dulu/ditalangi oleh pihak ojek) dan pihak ojek mengantar makanan kepada konsumen, dan konsumen membayar harga makanan secara tunai atau secara transfer melalui layanan GoPay yang disediakan pikak Go-Jek, yaitu metode pembayaran melalui cara top-up dengan saldo minimal Rp 100.000. Harga yang harus dibayar oleh konsumen terdiri dari tiga komponen seperti berikut: (1) harga makanan; (2) ongkos kurir; dan (3) biaya kirim. Ongkos kirim misal dipatok Rp 26.000 untuk dalam kota (radius $6 \mathrm{~km}$ misalnya) dan ada tambahan Rp 5.000 per $1 \mathrm{~km}$ jika di luar radius $6 \mathrm{~km}$. Sedang ongkos kirim itu sendiri merupakan biaya pemesanan melalui fitur secara online yang dipatok sebesar Rp 10.000 (Yusufin \& Adelia, 2018).

Dalam transaksi aplikasi Go-Jek dengan layanan Go-Food terdapat hal-hal yang menimbulkan khilafiyah dikalangan para Mujtahid. Sebagian ada menghukumi 
dengan haram, sedangkan sebagian yang lain ada menghukumi dengan status halal. Tentu hal ini menimbulkan keresahan ditengah-tengah masyarakat atau ummat Islam sendiri, khususnya yang berdomisili di daerah perkotaan dengan aktifitas yang padat. Misalnya, dalam lingkup yang kecil di daerah tempat tinggal penulis ada sebagian ulama yang mengharamkan jual beli online dengan alasan karena jual beli harus saling bertemu supaya tidak seperti istilah membeli kucing didalam karung. Dengan adanya perbedaan di lingkungan kecil penulis maka tentu akan ada juga perbedaan di lingkungan yang lebih besar. Karena dengan hadirnya aplikasi Go-Jek dengan jenis layanan Go-Food, sangat membantu mereka khususnya dalam memperoleh makanan atau minuman. Masyarakat tidak perlu memasak dan tidak perlu keluar rumah, cukup dengan memanfaatkan aplikasi yang terdapat dalam smartphone, konsumen juga bisa memilih makanan dan minuman sesuai dengan selera (Syahid, 2018). Oleh karena itu, penelitian ini akan mengkaji Implementasi Pembelian Makanan Online Melalui Layanan Go-Food dalam Perspektif Hukum Islam.

\section{MATERI DAN METODE}

\section{Jual Beli Online}

Jual beli merupakan salah satu muamalah yang diatur sudah diatur dalam Islam. Yang dimaksud dengan muamalah ialah tukar menukar barang dan jasa atau sesuatu yang memberi manfaat dengan cara yang ditentukan, sedangkan pengertian jual beli sendiri adalah menukar suatu barang yang lain dengan cara yang tertentu (akad). Sebagaimana hukum dasar dari muamalah menurut Islam. Bisnis jual beli online hukumnya diperbolehkan selama tidak mengandung unsur-unsur seperti kezhaliman, penipuan, riba, kecurangan, dan lain sebagainya.
Akad merupakan unsur penting dalam suatu bisnis dan untuk kasus titip beli yang menggunakan jasa Go-Food terdapat dua akad yang terjadi dalam transaksi tersebut yaitu akad ijarah dan akad qardh. Akad ijarah (sewa) akan terjadi pada saat pelanggan telah memesan makanan pada aplikasi Go-Jek dan meminta driver Go-Jek untuk mengantarkan makanan yang dipesan pelanggan ke tempatnya, kemudian pelanggan membayar ongkos kirim kepada driver Go-Jek tersebut. Pelanggan di sini berlaku sebagai penyewa jasa, sedangkan pengemudi sebagai penyedia jasa, dan ongkos kirim yang dibayarkan sebagai upahnya. Sedangkan akad qardh (hutang) terjadi ketika pengemudi menalangi terlebih dahulu pembayaran pesanan dari pelanggan yang kemudian diganti oleh pelanggan pada saat pengemudi mengantarkan pesanan tersebut, maka pengemudi berlaku sebagai pemberi pinjaman dan pelanggan sebagai peminjam. Pada dasarnya hukum akad qardh dalam jual beli adalah mubah (boleh) selama didalamnya tidak ada unsur riba atau pertambahan untuk pemberi pinjaman/utang, dalam hal ini terdapat larangan Nabi shallallahu alaihi wa sallam menggabungkan akad pinjaman dengan akad jual beli:

$$
\text { لا يَحِلُّ ستَلَفَ و بَيْعِ }
$$

Artinya: "tidak halal menggabungkan antara akad pinjaman dan jual beli" (HR. Abu Daud. Menurut Al-Albani Derajat Hadis Ini Hasan Shahih) (Tarmizi, 2017).

Selain hadis di atas para ulama sepakat haramnya melakukan penggabungan akad pinjaman dan jual beli. Ijma' ini dinukil oleh Al-Qarafi yang mengatakan bahwa umat Islam telah sepakat bahwa hukum jual beli dan utang piutang yang terpisah kedua akad tersebut hukumnya dibolehkan dalam Islam, akan tetapi menjadi haram apabila menggabungkan kedua akad tersebut 
dalam satu akad, karena hal ini dapat mendatangkan celah untuk terjadinya riba (Al-Qorofi, 1998).

\section{Sejarah munculnya Aplikasi Go-Jek dan Deskripsinya}

Bermula di tahun 2010 sebagai perusahaan transportasi roda dua yang dalam operasional dan pemesanannya melalui panggilan telepon. Go-Jek kini telah tumbuh menjadi on-demand mobile platform dan salah satu aplikasi terdepan yang menyediakan berbagai layanan lengkap mulai dari pembayaran, transportasi, logistik, layan-antar makanan, dan berbagai layanan ondemand lainnnya (Go-Jek, 2019). Go-Jek telah menghubungkan pengguna dengan lebih dari 1 juta mitra driver ojek dan mobil, lebih dari 125 ribu pedagang kuliner, dan 30 ribu penyedia layanan lainnya. (Go-Jek P. , 2019)

Go-jek telah beroperasi di 50 kota di Indonesia, seperti Jakarta, Bandung, Surabaya, Bali, Makassar, Medan, Palembang, Semarang, Yogyakarta, Balikpapan, Malang, Solo, Manado, Samarinda, Batam, Sidoarjo, Gresik, Pekanbaru, Jambi, Sukabumi, Bandar Lampung, Padang, Pontianak, Banjarmasin, Mataram, Kediri, Probolinggo, Pekalongan, Karawang, Madiun, Purwokerto, Cirebon, Serang, Jember, Magelang, Tasikmalaya, Belitung, Banyuwangi, Salatiga, Garut, Bukittinggi, Pasuruan, Tegal,Sumedang, Banda Aceh, Mojokerto, Cilacap, Purwakarta, Pematang Siantar, dan Madura serta pengembangan di kota-kota lainnya pada tahun mendatang (Go-Jek, 2019).

Go-Jek adalah on-demand mobile platform yang didesain dan ditawarkan oleh PT. Aplikasi Karya Anak Bangsa Indonesia dan merupakan aplikasi terdepan, aplikasi ini telah didownload oleh pengguna lebih dari 50 juta orang. Telah mengalami beberapa pembaruan sistem pada aplikasi dan yang terakhir diperbarui pada 09 Juli 2019, sementara alamat pengembangannya berlokasi $\mathrm{di}$
Pasaraya Blok M Gedung B Lt.6, Jalan Iskandarsyah II No.7 RW.2, Melawai, Kebayoran Baru, RT.03/RW.01 Kota Jakarta Selatan, 12160, Indonesia (Go-Jek P., 2019).

\section{Metodologi Penelitian}

Jenis penelitian yang digunakan dalam penelitian ini adalah kualitatif yang menggunakan metode fenomenologi. Metode fenomenologi ini dipilih karena dianggap sesuai dengan penelitian penulis, yang akan dipakai untuk melihat suatu fenomena yang terjadi pada kegiatan jual beli makan online melalui jasa Go-Food yang berlangsung di Bogor yang kemudian akan dianalisis dengan hukum Islam.

Sumber data yang digunakan berasal dari data primer dan data sekunder. Data primer dalam penelitian ini diperoleh dari hasil wawancara, observasi dan dokumentasi pada tiga objek yang meliputi driver Go-Jek, konsumen dan tokoh masyarakat (ulama). Sedangkan data sekunder diperoleh dari buku-buku, jurnal, internet dan bahan pustaka lainnya yang membahas tentang tinjauan hukum Islam terhadap jual beli makanan online melalui aplikasi Go-Food di Bogor.

Teknik pengumpulan data sering juga disebut dengan metode pengumpulan data, dalam metode ini yang digunakan dalam pengumpulan data adalah metode library research atau kajian kepustakaan, wawamcara, dan observasi. Teknik kajian pustaka ini menelusuri data-data hukum Islam, yaitu pasal-pasal Peraturan Mahkamah Agung Nomor 2 Tahun 2008 tentang Kompilasi Hukum Ekonomi Syariah, kitab-kitab, jurnal, peraturan perundang-undangan, buku dan sumber lainnya yang berkaitan dengan implementasi pembelian makanan online melalui layanan Go-Food dalam perspektif hukum Islam. Sedangkan wawancara yang digunakan dalam penelitian ini adalah wawancara tidak terstruktur. Dengan wawancara 
tidak terstruktur ini, penulis tidak menggunakan pedoman wawancara secara sistematis dan lengkap untuk pengumpulan data yang mengenai tinjauan hukum Islam terhadap jual beli makanan online melalui aplikasi Go-Food di Bogor. Wawancara ini dilakukan kepada karyawan atau driver Go-Jek, konsumen dan tokoh masyarakat (ulama) yang berkaitan dengan praktik jual beli makanan online melalui jasa Go-Food di Bogor. Adapun observasi yang digunakan oleh peneliti adalah metode observasi non partisipan. Pada observasi ini, peneliti tidak terlibat langsung dalam kehidupan orang-orang yang akan diobservasi, melainkan hanya mengamati proses kegiatan jual beli makanan online melalui jasa Go-Food.

Analisis data yang digunakan adalah fenomenologi. Menurut Cresswell (1998) fenomenologi menjelaskan suatu fenomena dan maknanya bagi individu dengan melakukan sebuah wawancara pada sejumlah individu tertentu. Selanjutnya dihubungkan dengan prinsipprinsip filosofis fenomenologi dan studi ini diakhiri dengan esensi dari makna. Berikut ini adalah tahapan penelitian analisis data fenomenologi menurut Colaizzi (1978):

1. Peneliti mendeskripsikan sepenuhnya fenomena yang dialami subjek penelitian. Seluruh rekaman dari hasil melakukan wawancara mendalam dengan subjek penelitian ditranskripsikan ke dalam bahasa tulisan.

2. Tahap Horizonalization, yaitu tahap melengkapi data dari berbagai sumber yang sesuai dengan penelitian yang akan dilakukan. Selanjutnya, dari hasil transkripsi, peneliti mengumpulkan atau menginventarisasi data dengan mengumpulkan pernyataan pernyataan penting yang relevan dengan topik.

3. Tahap cluster of meaning: selanjutnya peneliti melakukan analisis dengan mengklasifikasikan pernyataanpernyataan yang sudah dibuat tadi ke dalam tema-tema atau unit-unit makna. Pada tahap ini dilakukan Textural description (deskripsi tekstural): peneliti menulis apa yang dialami, yakni deskripsi tentang apa yang dialami individu; dan Structural description (deskrispsi struktural): peneliti menuliskan bagaimana fenomena itu dialami oleh para individu. Peneliti juga harus mencari makna berdasarkan peneliti sendiri, berupa opini, perasaan penilaian, harapan subjek penelitian tentang fenomena yang dialaminya.

4. Tahap deskripsi esensi: peneliti mengonstruksi atau membangun deskripsi secara menyeluruh mengenai makna dan esensi pengalaman para subjek penelitian.

5. Peneliti melaporkan hasil penelitiannya.

\section{HASIL DAN PEMBAHASAN}

\section{Praktik Pemesanan Makanan Melalui Layanan Go-Food pada Aplikasi Go-Jek}

Go-Food adalah layanan jasa sistem online dalam bentuk melakukan beli dan antar makanan yang telah dipilih oleh pelanggan sesuai pilihan menu dari restoran atau kedai yang terdapat pilihannya pada aplikasi Go-Jek, yang kemudian akan ditemukan seorang pengendara (driver) yang bersedia membelikan dan mengantarkan pesanan makanan oleh pelanggan tersebut, dengan pembayaran melalui Go-Pay di awal transaksi atau pembayaran tunai di akhir transaksi (Go-Jek, 2019). Sebelum melakukan pemesanan dengan aplikasi Go-Food. Setiap pihak Go-Jek harus memiliki akun terlebih dahulu.

Pelanggan memiliki akun pada aplikasi Go-Jek untuk menghubungkan dirinya dengan driver dan warung. Driver memiliki akun pada aplikasi driver Go-Jek untuk menghubungkan dirinya dengan 
pelanggan dan warung/restoran. Sedangkan warung/restoran memiliki akun pada aplikasi Go-Resto untuk menghubungkan perusahaan/bisnisnya dengan pelanggan dan driver. Untuk menjaga keamanan terdapat beberapa syarat yang harus dipenuhi oleh mereka terutama identitas yang asli dan nomor telepon.

\section{Pendapat Ulama Terhadap Praktik Pemesanan Makanan Melalui Layanan Jasa Go-Food}

Setelah penulis membuat analisis pada praktik pemesanan makanan melalui jasa Go-Food pada aplikasi GoJek, selanjutnya penulis akan menganalisisnya dengan menggunakan hukum Islam. Berikut adalah beberapa pendapat Ulama kontemporer yang penulis ambil melalui youtube, kajian Majlis dan Wawancara:

1. Buya Yahya

Buya Yahya menggambarkan GoFood dan Go-Pay seperti ada satu orang atau lebih yang dia akan menjembatani saya dan orang yang memiliki mobil, bisa saja individu atau sistem. Go-Pay merupakan team yang akan membantu menghubungkan saya dengan penjual mobil menggunakan sistem. Jika saya ingin membeli mobil langsung bisa saja saya kesulitan mencari nomor telponnya, mungkin jika tahu akan terbatas. Maka, dengan team atau dengan aplikasi ini akan memudahkan kita dalam melakukan pemesanan, karena team ini memiliki link yang banyak tentang apa yang ingin kita beli. Hal ini merupakan suatu kemudahan yang dihadirkan untuk manusia.

Hukum pembelian makanan melalui layanan Go-Food hal ini dibagi menjadi dua. Pertama, Kita dengan Go-Pay terkait pemberian uang kepada pihak Go-Pay dan yang kedua adalah pihak Go-Jek dengan drivernya. Dalam hal ini harus memperhatikan akadnya saat kita melakukan transaksi dengan pihak GoPay, jika akadnya hutang/pinjaman maka harus dikembalikan hal ini menjadi haram apabila kita mendapatkan diskon/tambahan bonus karena merupakan riba. Tetapi, halal apabila akadnya adalah membayar jasa makanan yang akan dibeli, misalnya saya berikan uang ini, nanti jika saya ingin membeli makanan itu silahkan gunakan uang ini untuk membayar makanan itu. Apabila terdapat bonus/cashback dari pembelian makanan, maka hal ini diperbolehkan sebab akad awalnya kita memberikan uang untuk melakukan pembayaran bukan untuk meminjamkan. Karena bonus merupakan cara penyedia layanan Go-Pay untuk menarik konsumen agar pengguna aplikasi tersebut semakin banyak menggunakan jasa mereka. Selanjutnya pihak Go-Jek dengan driver merupakan sesuatu yang halal karena kita menggunakan jasa pengiriman dan membayar jasa merupakan kewajiban kita sebagai pengguna jasa. Maka dengan ini terbentuk sebuah kesepakatan dimana pembelian makanan melalui layanan GoFood membayar makanan dan jasanya (Yahya, 2019).

\section{Ustad Dr. H. Sutisna, MA}

Go-Food merupakan perkembangan zaman yang tidak dapat dihindari. Hal ini merupakan bentuk kemudahan didalam pemanfaatan teknoligi, sesuai dengan perkataan Sahabat Nabi Ali Bin Abi Thalib: "Didiklah anak-anakmu sesuai dengan zamannya, karena mereka hidup bukan di zamanmu". Sehingga mengikuti perkembangan zaman dengan menggunakan layanan Go-Food tidak dilarang di dalam Islam, selama ketetentuan-ketentuannya tidak dilanggar. Contohnya, tidak unsur riba, gharar, penipuan, makanan yang mengandung zat yang haram, dan makanan yang cara mendapatkannya dengan cara yang haram.

Penggunaan pembayaran melalui cash lebih aman dibandingkan penggunaan melalui Go-Pay, karena ada perbedaan pendapat tentang hal ini. Melakukan pembayaran menggunakan 
layanan Go-Pay tidak riba selama tidak bertentangan dengan syariat Islam, akan tetapi bisa juga haram apabila terdapat unsur penyalahgunaan dana yang di Top Up ke pihak Go-Pay. Sedangkan apabila membayar dengan cash kita hanya menitip membeli makanan dan kita membayar makanan serta jasanya saja (Wawancara, 2019).

3. Ustadz Dr. Firanda Andirja, Lc., MA

Permasalahan pada Go-Pay adalah mengambil diskon dari Go-Pay jika tidak ada diskon maka hal ini menjadi tidak masalah. Bentuk Go-Pay secara global ada 3 pihak dalam hal ini, pertama pihak GoPay, kedua pihak konsumen dan yang ketiga adalah BI (Bank Indonesia). Bentuk muamalah antara pihak konsumen dengan pihak Go-Pay menurut pandangan beberapa ulama adalah pertama sharf (mata uang baru berbentuk e-money) hal ini dirasa tidak tepat sebab tidak ada transaksi jual beli didalamnya hanya Top Up yang bisa dibilang hanya menyimpan uang. Kedua, beli jasa (ijarah) hal ini tidak tepat karena misalnya kita Top Up Rp. 100.000,- maka tidak ada kejelasan kita ingin membeli apa dengan uang itu dan untuk ongkos kemana uang itu. Ketiga, titipan (wadi'ah) hal ini juga tidak tepat sebab yang namanya titipan tidak dapat digunakan oleh orang lain. Sedangkan dalam kasus Go-Pay uang yang masuk dikelola oleh pihak perusahaan dengan bekerjasama dengan $\mathrm{BI}$.

Transaksi antara konsumen dan GoPay merupakan hutang bukan titipan. Contoh sederhananya adalah Arif memberikan uang kepada Anton, kemudian Anton tanya bolehkah saya memakai uang ini untuk Doni membuka usaha? Boleh, Jawab Arif. Dari sini dapat disimpulkan bahwa hal semacam ini adalah pinjaman sebab yang dinamakan titipan itu tidak boleh dipinjamkan. Secara umum konsumen Go-Pay membantu melakukan proses riba. Karena Saldo yang kita Top Up kepada Go-Pay 70\%nya dikelola oleh BI kemudian bunganya diberikan kepada pihak Go-Pay dan bunga tersebut diberikan kepada konsumen Go-Pay. Maka, sangat jelas jika menurut beliau hukum pembelian makanan melalui layanan Go-Food menggunakan layanan Go-Pay haram (Andirja, 2019).

4. Ustad Dzulkarnain Muhammad Sunusi Beliau tidak setuju apabila Top Up terhadap Go-Pay itu merupakan pinjaman. Hal itu seperti memaksakan hukum, padahal konsumen perlu jasa dan jasa tersebut harus dibayar. Pada dasarnya yang dilakukan adalah mengisi saldo (Top Up) kepada Go-Pay untuk kita gunakan saat kita perlu untuk membeli sesuatu keperluan yang ada pada Go-Jek. Menurut Ibnu Qudamah Rohimakumullahu ta'ala: "Jika ia membeli suatu barang dengan harga 1,5 dinar lalu kepada si penjuan ia memberikan 2 dinar. Dan ia berpesan engkau adalah wakilku pada $1 / 2$ dinar yang tersisa. Maka menurut Ibnu Qudamah Rohimakumullahu ta'ala berkata hal ini sah". Maka hal ini menurutnya bukan termasuk meminjamkan. Karena apabila dipaksakan menjadi peminjaman maka akan mutlak memaksa orang untuk sefaham dan berujung kepada hal yang hukum peminjaman. Sedangkan hukum Go-Food ada yang mengatakan haram karena dianggapnya hal ini merupakan pinjaman saat driver Go-Jek menalangi untuk membelikan makanan. Padahal jika kita cermati hal ini menguntungkan kedua belah pihak yang sesuai dengan kaidah fiqh. Seandainya mengharuskan driver mengambil dulu uang kepada konsumen kemudian pergi membeli makanan maka akan merugikan driver. Jadi penggunaan layanan Go-Food pada aplikasi Go-Jek tidak diharamkan dalam Islam (Sunusi, 2018).

\section{Analisis Hukum Islam Terhadap Praktik Pembelian Makanan Online Melalui Layanan Go-Food}

Berdasarkan kajian dan analisa terhadap pendapat berbagai ulama. 
Praktik pemesanan makanan melalui GoFood ini adalah dengan akad ijarah yang termasuk kategori sewa jasa, sebagaimana pengertian ijarah adalah upah atas pemanfaatan suatu benda atau imbalan suatu kegiatan, atau upah karena melakukan sesuatu aktivitas (Antonio, 2015). Bentuk aktifitas yang dilakukan oleh penyewa jasa (driver) disini adalah dalam bentuk mengambil pesanan makanan dan mengirimkannya yang telah dipilih dan dibayar oleh pelanggan melalui aplikasi Go-Jek dengan saldo GoPay atau dengan jasa membelikan terlebih dahulu dengan uang milik driver atas pesanan makanan yang dipilih oleh pelanggan melalui aplikasi Go-Jek dengan pembayaran tunai di akhir transaksi yang dibayarkan pada driver beserta upahnya.

Apabila ditinjau dari kelengkapan empat rukun ijarah sebagaimana yang ditetapkan oleh jumhur ulama adalah sebagai berikut (Karim, 1993):

1. Aqid, yaitu orang yang menyewakan ( $m u$ 'jir) adalah pihak driver Gojek dan orang yang menyewa (musta'jir) adalah para konsumen layanan Gofood.

2. Sighat, yaitu perbuatan yang menunjukkan terjadinya akad berupa ijab qabul. Adapun bentuk ijab yang lakukan saat proses pemesanan Gofood adalah ketika konsumen telah menentukan pilihan makanan apa yang hendak ia pesan dan telah setuju dengan taksiran harga dan biaya pengirimannya kemudian menekan tombol pesan. Sedangkan untuk bentuk ijabnya adalah dengan konfirmasi yang dilakukan oleh driver Go-jek kepada konsumen. Bentuk ijab dan qabul yang dilakukan antara konsumen dan driver dilakukan dengan sistem online.

3. Ujrah atau uang sewa atau upah, yaitu uang tarif atau upah yang diberikan kepada driver Go-Jek atas jasa pengantaran makanan yang telah ditentukan oleh aplikasi berdasarkan jarak tempuh antara lokasi pembelian pesanan dan pengantaran.

4. Manfaat, adalah bentuk pelayanan driver untuk membelikan sekaligus mengantarkan pesanan kepada konsumen Go-food.

Rukun ijarah di atas ditinjau berdasarkan syarat rukun ijarah yang dikemukakan oleh Imam Nawawi yang berupa syarat bentuk manfaatnya diketahui, manfaatnya diperbolehkan menurut syara' dan upah atau bayarannya diketahui (Nawawi, 2012). Maka rukun syarat ijarah dalam pemesanan makanan melalui layanan Gofood tersebut telah terpenuhi syaratnya. Syarat yang harus dipenuhi adalah berakal dan dapat membedakan yang haq dan batil (mumayyiz) menurut mazhab Hanifah (Syafei, 2000). Maka bisa dilihat dari ketentuan awal dalam penggunaan aplikasi Go-Jek, seperti salah satu syarat untuk menjadi driver Go-Jek yang harus memilki Surat Izin Mengemudi (SIM) yang minimal berusia 17 tahun. Terkait usia konsumen pengguna layanan jasa Go-jek tidak bisa dipastikan, namun tentang kecakapan dalam menggunakan teknologi cukup bisa dijadikan tolak ukur seseorang itu berakal dan mumayyiz. Apabila diketahui terdapat anak kecil mumayyiz yang melakukan transaksi tersebut, maka hukumnya sah secara syar'i disertai izin dari walinya (Sabiq, 2017).

\section{KESIMPULAN DAN IMPLIKASI}

Berdasarkan penjelasan dari pembahasan di atas, maka dapat disimpulkan bahwa sesuai dengan tinjauan hukum Islam ulama terdapat perbedaan pendapat dalam menentukan hukumnya. Pertama yang menghalalkan karena transaksi pada pemesanan makanan pada layanan Go-Food bukan termasuk dari pinjaman tapi menggunakan akad wadi'ah (titipan). Apabila ada diskon atau cashback hal ini 
merupakan cara perusahaan aplikasi GoJek mencari pelanggan dengan memberikan pelayanan terbaik sehingga semakin banyak pengguna aplikasi Go-Jek maka semakin besar juga keuntungan yang didapatkan Go-Jek. Kedua, yang mengharamkan karena akad pada layanan Go-Food merupakan pinjaman. Sehingga mengambil kesimpulan bahwa tidak boleh menggabungkan akad pinjaman dengan jual beli. Ditambah dengan adanya diskon yang jika pemesanan pada layanan Go-Food dianggap hutang maka diskon merupakan tambahan riba.

\section{DAFTAR PUSTAKA}

Al-Qorofi, I. A.-S. (1998). Al-Furuq /Anwarul Buruq Fi Anwa'il Furuq jilid III. Beirut - Lebanon: Darul Kutub Al-Ilmiyah.

Andirja, F. (2019). Gambaran Gopay Secara Global - Ustadz Dr. Firanda Andirja, Lc, M.A. https://www.youtube.com/watch $? \mathrm{v}=\mathrm{XsQVE}$ XXROQ. Diakses pada tanggal 3 Februari 2019

Antonio, M. S. (2015). Bank Syariah dari Teori ke Praktik. Jakarta: Gema Insani.

Go-Jek. (2019). https://www.go-jek.com. Diakses pada tanggal 5 Maret 2019

Karim, H. (1993). Fiqh Mu'amalah. Jakarta: Rajawali Pers.

Mu'izz, \& Fitria, R. R. (2016). Kualitas Aplikasi Mobile Go Jek di Kalangan Masyarakat Kota Surabaya (Study Deskriptif Kualitas dan Kesuksesan Sistem Teknologi Informasi Aplikasi
Go Jek. Surabaya: Departemen Ilmu Informasi dan Perpustakaan Fakultas Ilmu Sosial Dan Ilmu Politik Universitas Airlangga Surabaya.

Nawawi, I. (2012). Fikih Muamalah. Jakarta: V Pres.

Sabiq, S. (2017). Sulaiman Al-Faifi Mukhtashar Fiqh Sunnah. Jakarta: Senja Publishing.

Syafei, R. (2000). Fiqh Mu'amalah. Bandung: Pustaka Setia.

Tarmizi, E. (2017). Harta Haram Muamalat Kontemporer. Bogor: Berkat Mulia Insani.

Sunusi, D. M. (2018). Tanya-jawab ini disampaikan pada kajian Tafsir AlQur'anil Karim pada 28 Jumadal Awal 1439 atau 14 Februari 2018 di Masjid As-Sunnah Makassar. Makassar:

https://www.youtube.com/watch $? \mathrm{v}=$ Rm3BDonAoyg. Diakses pada tanggal 10 Agustus 2019

Syahid, A. (2018). Go-Food dalam Tinjauan Cendekiaan Muslim. Jurnal Finansia, Vol. 01, No. 01, 114-120.

Yahya, B. (2019). Hukum Go Pay - Buya Yahya Menjawab. https://www.youtube.com/watch? $\mathrm{v}=$ bZVTODGUsco. Diakses pada tanggal 10 Agustus 2019

Yusufin, \& Adelia, A. (2018). Transaksi Jual Beli Melalui Jasa Go Food Dalam Perspektif Hukum Islam. Lampung: Fakultas Hukum Universitas Lampung Bandar Lampung. 